\title{
Social And Cultural Predictors Of Tattooing Among Athletes Of Federal Universities In Nigeria
}

\author{
Ekenedo, G. 0. \\ Department of Human Kinetics and Health Education \\ University of Port Harcourt, Nigeria \\ Elechi, S. 0. \\ Department of Human Kinetics and Health Education \\ University of Port Harcourt, Nigeria
}

\begin{abstract}
The cross-sectional study investigated the social and cultural predictors of tattooing among athletes of Federal Universities in Nigeria. Data was collected from a sample of 594 athletes using a validated structured questionnaire with a reliability index of 0.77 . . Data collected were analysed using the Statistical Package for Social Sciences (SPSS) version 21. Multiple regression and logistic regression were used to establish the joint and independent predictors of tattooing among the athletes. The findings of the study revealed that peer influence $(P=0.003)$, family influence $(P=0.000)$, personal achievement $(P=0.006)$ and academic background $(\mathrm{P}=0.000)$ were significant social predictors of tattooing among the athletes. Traditional $(\mathrm{P}=0.000)$ and religious beliefs $(P=0.000)$ were also found to be significant cultural predictors of tattooing among the athletes. It was concluded based on the findings that the practice of tattooing among Nigerian University athletes followed similar social influence pattern as in other parts of the world. Social marketing was recommended as a veritable tool for health education and communication to enhance informed decisions regarding tattooing among the athletes.
\end{abstract}

Keywords: Tattoo; Athletes; Social predictors; Cultural predictors; Nigeria.

\section{INTRODUCTION}

Tattooing has become increasingly popular especially among athletes and people in the entertainment industry. Tattoo which is a form of cosmetics used to modify the body by injecting ink into the dermal area of the skin [1] is not new in Nigeria. Traditional tattoo dates back to the pre-colonial days when it existed as tribal marks which served as symbols of identification for members of a particular religious or cultural group, or legitimate family member. During the TansAtlantic slave trade, slaves were marked with tattoos to prevent them from being rescued, thus increasing the use of tattoo at that time [2]. Other reasons for marking were tribal clan wars, beauty, witchcraft, and superstitious belief [3]. Hence, tattoo was performed deliberately for some cultural, religious/spiritual or sentimental reasons. 
Ekenedo, G. O. \& Elechi, S. O. (2020) Social And Cultural Predictors Of Tattooing Among Athletes Of Federal Universities In Nigeria. Advances in Social Sciences Research Iournal, 7(4) 423-430.

However, tattooing in modern day has taken a different colouration. It is seen as a mark of selfexpression and fashion and a way of seeking social relevance. It has become a form of personal branding especially among celebrities. Despite negative views (such as gangstarism, criminality, mark of punishment, symbol of rebellion against society, paganism) attached to it, tattooing among some members of the population still remain strong. Tattooing has gained stronger acceptance among many social groups transiting from generation to generation with diverse predictors, which has blown the practice to global acceptance. Celebrities like musicians, actors, athletes and the likes have popularized this art by flaunting different designs.

Tattoos are common place in almost all professional sports [4]. The author observed that in America, about $55 \%$ of all active NBA players have tattoo as compared to about $25 \%$ of the population of Americans with tattoo. This implies that athletes rank high among the number of people with tattoos. The popularity of tattoo has increased immensely among the young athletes as they want to emulate their favourite sports role models [5]. Some of the reasons athletes tattoo their bodies include to have a sense of belonging, alter their public image, feel powerful, bring good luck and ward off bad luck, honor God, family members, team members and hometown, to remind them of difficult times or humble beginnings or just to see how the tattoo will look like [6]. Thus tattoo remains a generational trend that has continued despite the enormous documented negative health, social, psychological and economic implications.

People who have tattoos on their body sometimes face social discrimination particularly in developing countries like Nigeria. They are not viewed with seriousness and are oftentimes regarded as deviants. Some employers may not want to employ a tattoo carrier, because the sight may repel costumers. Though the practice continues, it has been discovered that close to 1 of every 3 persons with tattoo regretted having it due to social, psychological or health reasons [7][8].

The negative health implications of the practice have been empirically recorded. Health problems associated with tattoo include: infections [9][10][8]; allergic reactions [11][12]; bruise and haematoma [13]; dermal conditions such as granulomas, dermatitis, eczematous eruptions, hyperkeratosis and keloids [14][15]; Magnetic Resonance Imaging (MRI) complications [16][14][17][18][13][19]; oedema and heart conditions [20][21][22]; skin cancer [14][8]; tetanus, hepatitis B \& C and HIV [23][24] among others. Regrettably, no media hype has been given to these medical discoveries, hence the practice continues among many some of who may be ignorant of the health effects.

Decision to wear tattoo or not is usually influenced by some factors which may be personal, social, cultural and so on. Social influence has been described as the change in behavior that one person causes in another, intentionally or unintentionally as a result of the way the changed person perceives themselves in relationship to the influencer, other people and society in general [25]. In his theory - The Theory of Social Influence which he propounded in 1958, Kelman identified four areas of social influence namely; Compliance, identification, internalization and conformity [25]. Compliance is a situation where a person responds unequivocally, clearly and absolutely to a request put forth by another person. Identification occurs when a person obviously changes behaviour or attitude as a result of the influence exerted on him by that person whom he likes, adores or respects. Internalization is a process whereby a person accepts a set of norm instituted by another or a group of people that are influential to him. Conformity is a change in behaviour or 
belief adopted by a person in order to belong to a particular group. University athletes in Nigeria are subject to being influenced in the various ways described above because there tends to be a lot of hero worshiping and peer conformity among athletes.

As much as Athletes compete among one another, they also admire and adore one another. The upcoming Athletes see the older successful ones as their mentors and role models, and so would emulate them in many things. Even non-athletes (especially the young ones) see the successful athletes as their role models and would also imitate them. The social influence exerted by the older athletes on the younger athletes and non-athletes as a result of this mentorship and role model syndrome is very high. This is expressed in their zealousness to copy their life style, one of which could be tattooing in order to align with their mentor and role model.

A young athlete or non-athlete who adores an older athlete because he is famous and successful would desire to be like him. The desire for the younger person to be like the older would make him to do most of the things that he does. Most successful athletes have tattoos on various parts of their bodies depicting different meanings. According to the social influence theory, the achievements of the athlete is what earned him admiration of others and this achievement is a very positive force that can make people to change their behavior to align with the great achiever (the athlete). Culture which is a peoples' way of life was viewed by Sanderson 1998 [26] as the total life and ways characteristic of the members of the society, including tools and patterned ways of thinking and acting that are learned and shared, and are not the direct product of biological inheritance. This implies that culture must be learned by observation and demonstration from one generation to the other. Norms, customs, rites of passage, values and folkways are some basic elements of culture. Since tattooing has cultural history, conformity with cultural values could be a factor that influences young athletes to indulge in the practice. Athletes from families that uphold such culture are more likely to accept and practice tattooing.

Rahim postulates that culture has influence on the knowledge, attitude and practice of the society [27]. Most behaviours are rooted on cultural background. Values represent what an individual appreciates and esteems highly. .Japan, for instance, has a traditional style of tattoos known as Muawari (resembles an un-buttoned vest), and another design like "full body suits" which covers the whole body. These designs depict different meanings; they are hand-made designs which take a lot of time and cause so much pain [28]. Some tribes in Nigeria such as Hausa, Fulani and the Kanuri use temporary tattoo, done with Lalli or Henna paint to adorn a bride [29]. In Egypt, tattoos are symbolic. Images such as the Eye of Horus, Ba, Scarab, Ankh, Anubis (god of the dead), Djed, Phoenix are tattooed on specific parts of the body like the back of the neck, hip, wrist, lower part of the back, ankle, shoulder or wrist as a symbol for protection, to experience life after death, spontaneity, preservation, stability of power, strength and a new life [30].

\section{METHODS}

The study adopted the cross sectional survey design. The population for the study comprised 765 athletes from 5 federal universities in the south-south geo-political zone of Nigeria (derived from the sports directorates of the institutions investigated) who participated in different sports in the following order: university of Port Harcourt- 75, university of Calabar - 78, university of Uyo - 101, university of Benin-160, FUPRE- 351. The $6^{\text {th }}$ Federal University of Technology, located in Otueke, Bayelsa state was used for pilot study to test the reliability of the instrument. The sample size was 
Ekenedo, G. O. \& Elechi, S. O. (2020) Social And Cultural Predictors Of Tattooing Among Athletes Of Federal Universities In Nigeria. Advances in Social Sciences Research Iournal, 7(4) 423-430.

594 athletes obtained using quota sampling. Ethical approval for the study was obtained from the University of Port Harcourt Research Ethics Committee. Data for the study was collected by means of a self-structured and validated anonymous questionnaire with a reliability index of 0.77 . The questionnaire is a modified four-point Likert scale of Strongly Agree (4pts), Agree (3pts), Disagree (2pts) and Strongly Disagree (1pt). Data collection was made possible through research assistants who were coaches and team captains because they had direct contact with the athletes. These Coaches and team captains administered the questionnaire to the athletes. Data collected were analysed using the Statistical Package for Social Sciences (SPSS) version 21. Multiple regression and logistic regression were used to establish the joint and independent predictors of tattooing among the athletes.

\section{RESULTS}

Table 1: Regression analysis showing peer group, family influence, personal achievement and academic background as predictors of tattooing among athletes in Federal Universities in southsouth, Nigeria

\begin{tabular}{|c|c|c|c|c|c|c|c|c|}
\hline Model & $\mathbf{R}$ & $\begin{array}{c}\mathbf{R} \\
\text { Square } \\
\end{array}$ & $\begin{array}{l}\text { Adjusted } \\
\text { R Square }\end{array}$ & $\begin{array}{l}\text { Std. Error of } \\
\text { the Estimate }\end{array}$ & $\begin{array}{l}\text { Durbin- } \\
\text { Watson } \\
\end{array}$ & p-value & $\boldsymbol{\beta}$ & $\begin{array}{c}\text { Decisio } \\
\text { n }\end{array}$ \\
\hline \multicolumn{9}{|c|}{ Peer group } \\
\hline 1 & $.123(\mathrm{a})$ & .015 & .013 & .48995 & .810 & 0.003 & -.123 & Reject \\
\hline \multicolumn{9}{|c|}{ Family influence } \\
\hline 1 & $.216(\mathrm{a})$ & .047 & .045 & .48202 & .898 & 0.000 & -.216 & Reject \\
\hline \multicolumn{9}{|c|}{ Personal achievement } \\
\hline 1 & $.113(\mathrm{a})$ & .013 & .011 & .49052 & .826 & 0.006 & -.113 & Reject \\
\hline \multicolumn{9}{|c|}{ Academic Background } \\
\hline 1 & $.233(\mathrm{a})$ & .054 & .053 & .48013 & .871 & 0.000 & -.233 & Reject \\
\hline
\end{tabular}

The predictor variables - peer group influence explained $1.5 \%$ of the variance $\left(R^{2}=.015\right.$, $\mathrm{F}(1,593)=9.077, \mathrm{p}=0.003)$; family influence explained $4.7 \%$ of the variance $\left(\mathrm{R}^{2}=.04 .7\right.$, $\mathrm{F}(1,593)=29.020, \mathrm{p}=0.000)$; personal achievement explained $1.3 \%$ of the variance $\left(\mathrm{R}^{2}=.013\right.$, $\mathrm{F}(1,593)=7.697, \mathrm{p}=0.006)$ and academic background explained $5.4 \%$ of the variance $\left(\mathrm{R}^{2}=.054\right.$, $F(1,593)=33.927, p=0.000)$. It was found that peer group influence, family influence, personal achievement and academic background all significantly predicted tattooing $(\beta=-.123, \mathrm{p}=0.003 . \beta=-$ $.216, \mathrm{p}=0.000 \beta=-.113, \mathrm{p}=0.006 \& \beta=-.233, \mathrm{p}=0.000$ respectively) among the athletes.

Table 2: Regression analysis showing Joint Social variables as predictor to tattooing among athletes in Federal Universities south-south, Nigeria.

\begin{tabular}{|c|c|c|c|c|c|c|c|c|}
\hline Model & $\mathbf{R}$ & $\begin{array}{c}\mathbf{R} \\
\text { Square }\end{array}$ & $\begin{array}{c}\text { Adjusted R } \\
\text { Square }\end{array}$ & $\begin{array}{c}\text { Std. Error of } \\
\text { the Estimate }\end{array}$ & $\begin{array}{c}\text { Durbin- } \\
\text { Watson }\end{array}$ & $\begin{array}{c}\text { P- } \\
\text { value }\end{array}$ & B & Decision \\
\hline 1 & $.259(\mathrm{a})$ & .067 & .061 & .47805 & .901 & .000 & -.117 & Reject \\
\hline
\end{tabular}

The social variables jointly explained $6.7 \%$ of the variance $\left(\mathrm{R}^{2}=.067, \mathrm{~F}(4,590)=10.596, \mathrm{p}=0.000\right)$. It was found that Academic background $(\beta=-.167, \mathrm{p}=0.001)$ and family influence $(\beta=-.117, \mathrm{p}=0.024)$ significantly predicted tattooing, with academic background recording a higher beta value. Other social variables peer group influence and personal achievement did not significantly predict tattooing as compared to family influence and academic background. 
Table 3: Regression analysis showing traditional beliefs as predictor to tattooing among athletes in Federal Universities south-south, Nigeria.

\begin{tabular}{|c|c|c|c|c|c|c|c|c|}
\hline Model & $\mathbf{R}$ & $\begin{array}{c}\mathbf{R} \\
\text { Square }\end{array}$ & $\begin{array}{c}\text { Adjusted R } \\
\text { Square }\end{array}$ & $\begin{array}{c}\text { Std. Error of } \\
\text { the Estimate }\end{array}$ & $\begin{array}{c}\text { Durbin- } \\
\text { Watson }\end{array}$ & P-value & $\boldsymbol{\beta}$ & Decision \\
\hline \multicolumn{7}{|c|}{ Traditional belief } \\
\hline 1 & $.196(\mathrm{a})$ & .038 & .037 & .48411 & .857 & 0.000 & -.196 & Reject \\
\hline \multicolumn{7}{|c|}{ Religious belief } \\
\hline 1 & $.229(\mathrm{a})$ & .052 & .051 & .48062 & .914 & 0.000 & -.229 & Reject \\
\hline
\end{tabular}

Traditional belief explained $3.8 \%$ of the variance $\left(R^{2}=.038, F(1,593)=23.675, p=0.000\right)$ while religious belief explained $5.2 \%$ of the variance $\left(R^{2}=.052 F(1,593)=32.650, p=0.000\right)$. It was found that traditional and religious beliefs significantly predicted tattooing $(\beta=-.196, \mathrm{p}=0.000 \& \beta=-.229$, $\mathrm{p}=0.000$ respectively) among the athletes.

Table 4: Regression analysis showing Joint cultural variables as predictors to tattooing among athletes in Federal Universities south-south, Nigeria.

\begin{tabular}{|c|c|c|c|c|c|c|c|c|}
\hline Model & $\mathbf{R}$ & $\begin{array}{c}\mathbf{R} \\
\text { Square }\end{array}$ & $\begin{array}{c}\text { Adjusted R } \\
\text { Square }\end{array}$ & $\begin{array}{c}\text { Std. Error of } \\
\text { the Estimate }\end{array}$ & $\begin{array}{c}\text { Durbin- } \\
\text { Watson }\end{array}$ & P-value & B & Decision \\
\hline 1 & $.242(\mathrm{a})$ & .059 & .055 & .47940 & .908 & 0.000 & -.173 & Reject \\
\hline
\end{tabular}

Multiple Regression was used to test if joint cultural variables significantly predict tattooing among athletes. The result of the regression analysis showed that significantly, cultural variables jointly explained $5.9 \%$ of the variance $\left(\mathrm{R}^{2}=.059, \mathrm{~F}(2,5191)=18.410, \mathrm{p}=0.000\right)$. It was found that religious belief $(\beta=-.173, p=0.000)$ significantly predicted more compared to traditional belief $(\beta=-.097$, $\mathrm{p}=0.046)$

\section{DISCUSSION OF FINDINGS}

The finding that peer group influence is a significant predictor of tattooing among athletes in Federal Universities south-south, Nigeria is expected because majority of athletes are young persons and one of the characteristics of young persons is that they are easily influenced by their peers. This finding corresponds to that of Mayers, Judelson, Moriarty and Rundell [31] who in their investigation on prevalence of body piercing and tattooing among university undergraduates, reported that members of a sport team could have an identical tattoo applied on a specified body part as a symbol of bondage. Also Armstrong, Owen, Roberts and Koch in their study on college students and tattoos: influence of image, identity, family and friends ascertained that friends significantly influenced the inscription of tattoos [32].

The finding that family influence is a significant predictor of tattooing is expected because family members are the first point of contact of every individual. Most of the family norms are adopted from childhood before a person becomes independent. The period of growing up among family members is a period of bondage among family members and certain influences are exercised among family members. Interestingly, Armstrong, Owen, Roberts and Koch [32] discovered that among family members only the sister is a significant influencer of tattooing among the group surveyed. This finding, however, was made among college students in the United States of America whose 
Ekenedo, G. O. \& Elechi, S. O. (2020) Social And Cultural Predictors Of Tattooing Among Athletes Of Federal Universities In Nigeria. Advances in Social Sciences Research Iournal, 7(4) 423-430.

belief system is different from the belief system of the subgroup in this current study. Nigeria is an African nation that still holds strongly to family system and values. A child in Nigeria must pass through the tutelage of biological parents and extended family members, thus family ties is still very strong and can influence acceptance or rejection of a practice.

It was also discovered that personal achievement is a significant predictor of tattooing among athletes in Federal Universities in south-south, Nigeria. This finding aligns with that of Dousti, Asadi and Jafary in their study among student athletes at the University of Mazandaran in Iran [33]. They reported that aesthetics, personal expression and self-identification ranked higher among other variables used for comparison. These variables are closely associated with personal achievements. Quaranta, Napoli, and Fasano, et al. also reported that the reasons for tattooing among freshmen of the University of Bari, Italy were to increase their aesthetic looks, distinguish them from others and to make them fashionable [34]. Mcconnelle found that 70\% of students of Pittsburg University, USA acquired body art for self-concept development [35]. This result is not surprising because athletes by nature like to express themselves and show off their skills. They like to attract attention and the sight of tattooing is basically a point of attraction irrespective of the fact that some may not like the images. What matters to the athlete at that particular time is what appeals to him.

The current study also revealed that academic background is a predictor of tattooing among athletes in Federal Universities south-south, Nigeria. It is however a weak predictor among the other social variables. This result agrees with the findings of Heywood, Patrick and Shelley in their study on demographic and behavioural correlates of tattooing, established that the higher the level of education, the less likely to be tattooed among males and females. It however contradicts the findings of an earlier study carried out by Yamada on westernization and cultural resistance of tattooing [28]. He asserted that in the past tattoos were adorned by labourers and geishas (common women), but in contemporary times intellectuals such as office workers, company executives and people of high ranking professions are tattooing their skin. Mayers, Judelson, Moriarty and Rundell agreed with Yamada in their finding that incidence of tattooing was fairly remarkable among fresh students than students in higher levels. This particular finding is surprising but can be justified by the fact that the concept of tattooing has taken a different and elitist connotation from what it used to be in the past. Thus environmental factors could be at play.

It was also revealed that traditional belief is a significant predictor of tattooing among athletes in south-south federal universities of Nigeria. This result is not expected on one hand because the university environment is an intellectual environment; hence it would be absurd for any individual to exhibit or practice traditional doctrines. It is also expected on the other hand because most athletes found in Nigerian universities are Nigerians by birth. It is important to note that traditional values are highly respected in Nigeria. Thus the finding is not in line with that of Dousti, Asadi and Jafary who ranked cultural tradition lower among other motivators of tattooing among student athletes [33]. The study also found out that religious belief is a significant predictor of tattooing. This finding does not also agree with the findings of Dousti, Asadi and Jafary that also ranked spirituality low among other predictors explored [33]. Galle et al identified only spirituality as a predictor but did not state whether it was significant or not [36]. This result is not also surprising for the same reason that most Nigerian university athletes are Nigerians by birth and Nigerians are highly religious people. Most major religions in Nigeria frown at tattooing. 


\section{CONCLUSION}

Based on the findings of the study, the researchers conclude that the practice of tattooing among Nigerian University athletes followed similar social influence pattern as in other parts of the world

\section{Implications of Findings for Health Education and Communication}

In the light of the above conclusion, the findings hold a lot of implications for health education and communication programming. Since social diagnosis has shown the overwhelming influence of peer group, family, personal achievement and cultural beliefs on the practice of tattooing, interventions should focus basically on social marketing using young sport celebrities among others, to market the health and social implications of tattooing so that athletes who engage in the practice do so based on a well informed decision.

\section{References}

1. Krucik, G.. Tattoo and piercing. 2014 Retrieved from www.healthline.com/health/beauty-skin-care-tattoopiercing-overview\#

2. Oyinlola, A.. Tribal marks: The Nigerian tattoo. The Nation Newspaper, June 20, 2017. Retrieved from www.thenationonlineng.net.tribal-mark-the-Nigerian-tattoo

3. Ozongwu, M. Tribal marks- the African tattoo. 2012 Retrieved from www.thisisafrica.me/tribal-marks-theafrican-tattoo/

4. Trip, A.. Why so many pro-athletes have tattoos. 2015 Retrieved from blog.importsteam.com/why-do-so-manypro-athletes-have-tattoo

5. Doutheth, M.. Popularity of tattoo has grown among young athletes. 2016Retrieved fromwww.nwitimes.com/sports/high-school/boys-basketball/popularity-of-tattoos-has-grown-among-youngathletes/article_f4dDe619-8ba6-5bod-aece-37506393a059.html

6. Eric, N..The most tattooed athletes. 2012 Retrieved from, from bleachreport.com/articles/1054662-the-mosttattooed-athletes

7. Michael, Y.. Beyond tattoo regrets: The public health dangers of tattoo. 2015 Retrieved from,www.huffingtonpost.com/michael-yaremchuk- md/tattoos-infection_b_2814444.html

8. Greg, H.. Tattoos affect your health: Long-term side effects ink has on your immune system and disease risk. 2016Retrieved from http://www.medicaldaily.com/ta

9. Haley, R.W\& Fisher, R. P. Commercial tattooing as a potential source of hepatitis C infection. Medicine, 200080. 134 -151. Doi:10.1097/00005792-200103000-00006

10. George, O.. Types of tattoo. 2015 Retrieved from www.themissinglinktattoo.weebly.com

11. Victor, E. Health talk: Tattoo risks. 2013 Retrieved from dominicannewsonline.com/news/homepage/columns/health-talk-tattoo-risks-side effects precaution

12. Marcola, J.. Nanoparticles in tattoos may cause Cancer. 2013 Retrieved fromarticles.marcola.com/sites/articles/archives/2013/11/20/nanoparticles-tattoo-ink.aspx

13. US Food and Drug Administration.. A tattoo for you? Seven key questions to consider. 2016 Retrieved fromwww.fda.gov/For Consumers/ConsumerUpdates/ucm316357.htm

14. Genser, J. The truth about tattoos: Health risks, toxicity and more. 2007 Retrieved from www.naturalnews.com/022073_tattoos_health_skin.html

15. Shinjini, C., Ankush, S\& Rohan, S. Illustrated medical Dictionary (2nd ed.) 2008. Singapore: Star standard industries

16. Tope, W. D \& Shallock, F. G.. Magnetic resonance imaging and permanent cosmetics (tattoo): Survey of complications and adverse events. Journal of Magnetic Resonance Imaging, 2002 15(2): p. 180 -184. Doi: 10.1002/jmri.10049 PMID 11836774 
Ekenedo, G. O. \& Elechi, S. O. (2020) Social And Cultural Predictors Of Tattooing Among Athletes Of Federal Universities In Nigeria. Advances in Social Sciences Research Iournal, 7(4) 423-430.

17. Offret, H., Offret, M., Labetoulle, M and Offret, O.. Permanent cosmetics and magnetic resonance imaging. Journal Francaisd'Ophtalmologie, 2009 32(2): p. 131.el-3 doi:ioib/j.jfo 2008.07.002. PMID 20579475

18. US Department of Health and Services. Think before you ink. Are tattoos safe? 2015 Retrieved from www.fda.gov/for consumers/consumer updates/ucm048919.htm

19. Health24, Five dangerous health risks of tattoos. 2018 Retrieved from https://www.health24.com

20. Gretchen, R. How tattoo might affect your workout. 2017 Retrieved from https://www.nytime.com/2017/07/26/well/move/how.tattoos.might-affect-your-workout_htm? mcub2=o

21. Lizett, B. Getting a tattoo may change your body sweat during intense heat. 2017 Retrieved from. https://www.medicaldaily.com

22. Leukemier, M. J., Hanista, J. M \& Aho, K. M. Skin tattoos alter sweat rate and Na+concentration. Medicine \& science in sports and exercise, 2017 49(7): 1436 doi:10.1249/mss0000000000001244. Retrieved 26th July, 208 from https://www.depdyve.com

23. Farzon, A. N.. How safe is that tattoo? 2016 Retrieved from www.clinicalcorrelations.org/?p=4240

24. Philip, B.. EU research investigates health risks of tattoo and body piercing. 2003 Retrieved from europa.eu/rapid/pree-release_IP-03-1033_en.htm

25. Kelman HC. Compliance, identification, and internalization: Three processes of attitude change. Journal of Conflict Resolution, 19582 (1) : p.51-60. https://scholar.harvard.edu/hckelman/publications/compliance-identificationand-internalization-three-processes-attitude-change

26. Nwanna-Nzewunwa, O. P., Girigiri, B. K. \&Okoh, C. F. 2007. Social studies: Foundations, methods and contemporary social problems. 2003 Owerri Springfield.

27. Rahim, A. Principles and practice of community medicine. $2008 \mathrm{New}$ Dehli, India: Jaypee brothers medical.

28. Yamada, M. Westernization and cultural resistance of tattooing practices in contemporary Japan. International journal of cultural studies 2009 12(4): p. 319 - 338. Retrieved from http://opus.ipfw-edu/social_facpubs/7

29. Dary-Hubpages. History of traditional body art in Nigeria. 2015 Retrieved fromdarey.hubpages.com/hub/Historyof-traditional-body-art-in-Nigeria.

30. Asaff, B.. Egyptian Symbol tattoos. 2016 Retrieved from tattoo.lovetoknow.com/Egyptian_symbol_tattoos

31. Mayers, Judelson, Moriarty \& Rundell. Prevalence of body art (body pMayoclinic.org (2016).Tattoos: Understanding risks and precautions. 2001 Retrieved fromwww.mayoclinic.org/healthy-lifestyle/adulthealth/in-depth/tattoos-and-piercing/art-20045067

32. Armstrong, M. L., Owen, D.C., Roberts, A. C \& Koch, J. R. College students and tattoos: Influence of image, identity, family and friends. 2006 Retrieved from https://www.ncbi.nlm.nih.gov/pubmed/12385196[indexed for MEDLINE]

33. Dousti, H. A. \& Jafary, S. Motivators for getting tattooed in student athletes in Iran. International journal of sports studies. 2012, 2(8): p. 409 - 413. ISSN 2251 -7502@2012 Victor Quest publication: Retrieved from http://www.ijssjournal.com

34. Quaranta, A., Napoli, C., Fasano, F. et al. Body piercing and tattoos: a survey on young adults' knowledge of the risks and practices in body art. BMC Public Health 2011 11, 774. https://doi.org/10.1186/1471-2458-11-774,

35. Mcconnell, S. O.. Common motivators to acquiring body art among high school students in Pittsburg. 2009 Retrieved from http://www.nji.sagapub.com/context/10/bodyart/mo/refs

36. Galle, F., Mancusi, C., Di Onofrio, V.V., Alfano, V., Mastronuzzi, R., Guida, M \& Liguori, G. Awareness of health risks related to body art practices. 2011 Retrieved from https://www.ncbi.nlm.nih.gov/pmc/articles/pmc3223796/

37. Heywood, W., Patrick, K., Anthony, M., Smith, A., Simpson, J.M., Pitts, M. K....Shelley, J. M. (2012). Who gets tattoo? Demographic and behavioural correlates of ever being tattooed in a representative sample of men and women.

38. Annals of Epidemiology. 2012 Vol. 22(1) PP 51-56.Doi: 10.1016/j.annepide, 2011. 10.005.Retrieved from www.sciencedirect.com/science/article/pii/51047279711002870

39. WebMed (2015). Tattoos: What you need to know. Retrieved from www.webmed.com/skin-problems-andtreatments/tattoos-what-you-need-know. 